\title{
Aplikasi Penentuan Jalur Lokasi Penjemputan Mengunakan Algoritma Dijkstra
}

\author{
Abdul Fadlil ${ }^{1}$, Imam Riadi ${ }^{2}$, dan Moh. Saefuloh ${ }^{3}$ \\ Program Studi Teknik Elektro, Universitas Ahmad Dahlan Yogyakarta ${ }^{1}$ \\ Program Studi Sistem Informasi, Universitas Ahmad Dahlan Yogyakarta ${ }^{2}$ \\ Program Studi Teknik Informatika, Universitas Ahmad Dahlan Yogyakarta ${ }^{3}$ \\ fadlil@mti.uad.ac.id ${ }^{1}$,imam.riadi@is.uad.ac.id ${ }^{2}$, mohsaefulohuad@gmail.com ${ }^{3}$
}

\section{Article Info}

History :

Dikirim 07 November 2019

Direvisi 13 Desember 2019

Diterima 01 Maret 2020

Kata Kunci:

Djikstra

Estimasi Waktu Tempuh

Android

\begin{abstract}
Abstrak
Penentuan rute optimal merupakan suatu masalah yang sangat penting untuk dipecahkan karena berpengaruh terhadap waktu dan biaya operasional kendaraan. Penentuan rute optimal diperlukan untuk mendapatkan rute yang efisien. Salah satu permasalahan dalam penentuan jalur lokasi penjemput siswa di SMK Muhammadiyah Bumiayu, Kab. Brebes, Jawa Tengah itu sendiri dalam penetuan jalur lokasi penjemputan dengan menggunakan Algoritma Dijkstra. Di dalam Dijkstra itu sendiri merupakan salah satu algoritma yang digunakan untuk mencari jarak terpendek, untuk menentukan jalur lokasi penjemput antar siswa. Pengembangan sistem informasi yang dibuat dengan menggunakan Android digunakan untuk penentuan jalur lokasi penjemput siswa (Halte). Hasil yang didapatkan dari penentuan jalur lokasi penjemputan siswa adalah mampu menemukan jarak terpendek dan jarak terpendek alternatif ketika terjadi hambatan (pemblokiran jalan dan Kemacetan) pada jalur terpendek utama dan juga dapat mengetahui estimasi waktu tempuhnya. Tujuannya dan manfaat dengan adanya aplikasi penentuan jalur lokasi penjemputan dengan menggunakan Algoritma Dijkstra berbasis mobile adalah untuk menentukan efesiensi rute penjemputan berdasarkan halte sekolah, waktu tempuh dan jumlah penumpang sedangkan Manfaat adalah untuk mengguranggi angka indek keterlambatan siswa, memberikan kemudahan akses kepada siswa-siswi SMK Muhammadiyah Bumiayu untuk pepesanan penjemputan, memberikan efisiensi waktu penjemputan siswa dan meningkatkan nilai jual SMK Muhammadiyah Bumiayu.
\end{abstract}

(C) This work is licensed under a Creative Commons Attribution-ShareAlike 4.0 International License.

\section{Koresponden:}

Moh. Saefuloh

Program Studi Teknik Informatika

Universitas Ahmad Dahlan

Jl. Kapas No.9, Semaki, Kec. Umbulharjo, Yogyakarta 55166

mohsaefulohuad@gmail.com 


\section{PENDAHULUAN}

Perkembangan pola pikir masyarakat semakin hari semakin berkembang seiring dengan kemajuan pendidikan yang sekarang menjadi lebih baik. Jika pola mikir masyarakat dahulu yang menyekolahkan anaknya tidak jauh dari rumah dan agar dapat mudah pengawasannya. Akan tetapi beberapa orang tua mendapatkan masalah terhadap lokasi sekolah yang jauh, jalanan yang macet, atau tidak mempunyai kendaraan pribadi ataupun kegiatan orang tua yang padat pagi hari sehingga menjadi kendala bagi banyak orang tua. Transportasi umum menjadi salah satu pilihan masyarakat untuk beraktifitas [1]. Bus sekolah merupakan salah satu bentuk layanan transportasi yang ditawarkan oleh pihak sekolah. Masyarakat kini lebih memilih sekolah yang menawarkan layanan sekolah yang lebih baik untuk menunjang kegiatan yang berlangsung di sekolah. Tentunya sekolah pada era sekarang juga berlomba-lomba untuk menarik minat masyarakat, dengan terus berbenah dan mencoba memberikan layanan yang lebih baik.

Layanan transportasi sekolah (Mobil Jemputan) merupakan sarana transportasi bagi siswa untuk kelancaran proses belajar mengajar karena siswa akan merasa aman dan tidak terlambat maupun membolos juga dapat masuk dengan tepat waktu. Sehingga fasilitas antar jemput adalah solusi untuk masalah tersebut. Akibat terkadang muncul kekhawatiran apakah anak sudah diantar atau dijemput. Dengan kemajuan teknologi saat ini kekhawatiran orang tua dapat teratasi dengan adanya aplikasi penjemputan khusus di SMK Muhammadiyah Bumiayu, Kabupaten Brebes Jawa Tengah. Penulis menilai pembuatan aplikasi berbasis android dapat menjadi alternatif solusi. Hal itu dikarena android merupakan platform yang lengkap, mulai dari sistem informasi, apliksi, developing tool atau alat pengembang, pasar aplikasi, serta dukungan vendor industri [2].

Metode ini dinamakan penentuan posisi secara global karena koordinat yang dihasilkannya bersifat geosentrik, artinya pusat masa bumi dianggap sebagai pusat sistem koordinat sehingga sistem koordinat ini berlaku untuk seluruh dunia [3]. Aplikasi didalam sistem operasi android sering dijumpai pada umumnya merupakan sistem operasi berbasis Linux. Platform aplikasi disediakan secara bebas untuk mengembangkan aplikasi Android sendiri bagi siapa saja. Sistem operasi Android memiliki platform open source sehingga programmer yang membuat dan memodifikasi aplikasi Android sangat banyak [4]. Salah satu metode pencarian jarak terdekat adalah dengan menggunakan algoritma dijkstra yang Berbasis Mobile. Berdasarkan keadaan tersebut, perlu dibangun sebuah Aplikasi Penentuan Jalur Lokasi Penjemputan Menggunakan algoritma diskstra Berbasis Mobile. Dengan sistem operasi android yang memanfaatkan fitur GPS yang ada di dalam smartphone. Aplikasi android juga telah digunakan untuk informasi pengenalan satwa di kebun binantang dengan memanfaatkan koordinat GPS dari kandang satwa yang dikunjungi oleh pengunjung [5].

Pada perangkat mobile, sistem notifikasi memainkan peranan yang utama yaitu memberitahu user dengan segera terhadap datangnya sebuah pesan, event, atau action baru, keunggulan sistem notifikasi mobile seperti ini dapat dimanfaatkan sebagi cara untuk mengatasi kelemahan layanan informasi lokasi jalur penjemputan [6]. Aplikasi mobile sebagai sarana media promosi produk bagi usaha mikro kecil dan menengah serta menginformasikan lokasi layanan perbankan terdekat usaha tersebut [7]. Berdasarkan pendahuluan diatas, yang akan dibangun harus mampu mengolah pesan yang masuk menggunakan algoritma dijkstra untuk menghasilkan jalur terpendek lokasi penjemputan siswa. Sistem Informasi juga harus mampu menentukan jalur lokasi titik kumpul penjemputan siswa. Pesan yang masuk ke sistem difasilitasi dengan menggunakan mobile. Fungsionalitas lainnya yang harus dimiliki oleh sistem adalah mampu melakukan pelacakan lokasi menggunakan teknologi GPS.

\section{METODE PENELITIAN}

Metode yang digunakan dalam mengembangkan Aplikasi ini adalah Metode air terjun atau yang sering disebut metode waterfall sering dinamakan siklus hidup klasik (classic life cycle). Langkah awal dalam penelitian ini yang dilakukan adalah mengumpulkan data baik data primer maupun data sekunder, kemudian dilakukan dengan observasi, wawancara dan studi dokumentasi atau analisis arsip dan dokumen-dokumen yang digunakan dalam proses pengelolaan antrian. Selanjutnya metode waterfall ini mengusulkan sebuah pendekatan kepada pengembangan perangkat lunak yang sistematik dan sekuensial yang mulai pada tingkat dan kemajuan sistem pada sebuah planning, analisis, desain, coding dan pengujian [8]. Untuk lebih jelasnya tahap-tahap dari paradigma waterfall dapat dilihat pada gambar 2.

Pada Gambar 2 terdapat penjelasan di dalam metode penelitian diantara nya :

\section{Analysis}




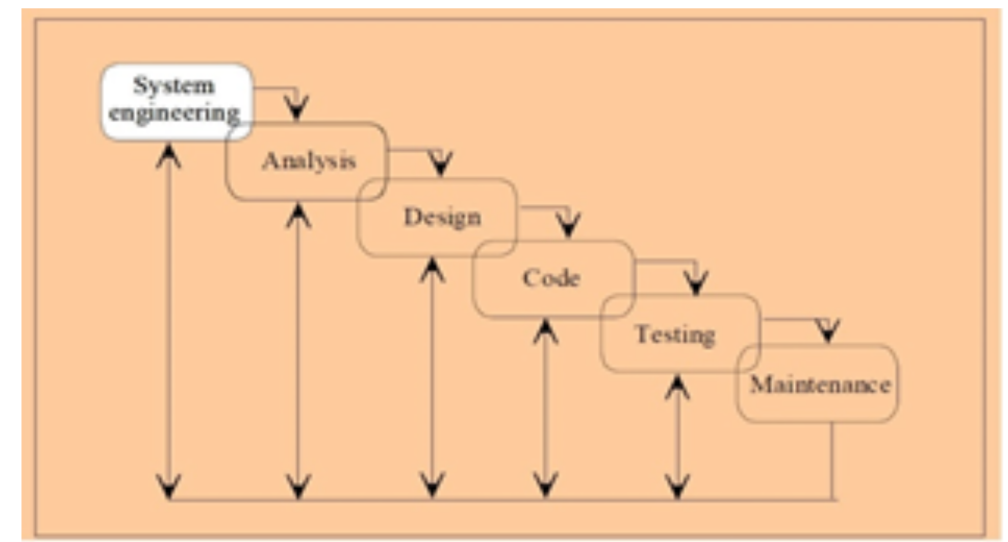

Gambar 1. Paradigma Waterfall

Pada tahap ini peneliti melakukan analisis pada SMK Muhammadiyah Bumiayu, terkait dengan masalah penjemputan siswa agar tidak terlambat kesekolah. Dari hasil analisis sekolah peneliti mencari kebutuhan untuk memenuhi pembuatan aplikasi

2. Design

Proses design ini peneliti melakukan design dengan menggunakan Balsamiq Mockup, untuk membuat design dari aplikasi yang akan di buat sedangkan untuk kebutuhan design pada saat menggembangkan aplikasi peneliti menggunakan Photoshop CS6.

3. Code

Setelah tahap analisis dan design dipenuhi, maka langkah selanjutnya adalah menerapkan kedalam bentuk Coding. Adapun bahas pemrogrman yang di gunakan adalah bahasa Java dengan menggunakan Android Studio.

4. Testing

Setelah aplikasi selesai di buat peneliti mengguji coba aplikasi untuk mengetahui apakah aplikasi sudah berjalan sesuai yang diharapkan oleh peneliti.

5. Maintenace

Untuk pengambilan biodata siswa-siswi yang akan digunakan dalam penjemputan siswa maka selaku peneliti memperoleh data penelitian di SMK Muhammdiyah Bumiayu Kab Brebes Jawa Tengah, untuk pengambilan data alamat dan nomer telp siswa-siswi.

\subsection{Objek Penelitian}

Pada penelitian ini, penulis mengambil objek penelitian di SMK Muhammdiyah Bumiayu Kab Brebes Jawa Tengah, untuk pengambilan data alamat dan nomer telp siswa-siswi.

\subsection{Alat dan Bahan}

Pada Tabel 2 adalah Hardware dan sofware yang digunakan dalam pengembangan laporan tesis sebagai berikut :

Tabel 1. Lingkungan Pengembangan System.

\begin{tabular}{llll}
\hline No & Perangkat & \multicolumn{1}{c}{ Spesifikasi } & \multicolumn{1}{c}{ Kegunaan } \\
\hline 1 & Laptop & Intel I3-6006U 2.0GB, RAM 4GB, HDD1T & Perangkat pembuatan dan pengujian aplikasi \\
2 & Android Studio & Samsung Galaxy Grand Duos & IDE untuk pengembangan aplikasi \\
3 & SDK & SDK 7 & Meng-compile aplikasi \\
4 & Photoshop & CS6 & Membuat desain interfase \\
5 & MySQL & MySQL & Database server \\
\hline
\end{tabular}




\section{LANDASAN TEORI}

\subsection{Algoritma Dijkstra}

Merupakan algoritma yang termasuk dalam algoritma greedy, yaitu algoritma yang sering digunakan untuk memecahkan masalah yang berhubungan dengan suatu optimasi. Di bawah ini diberikan contoh sebuah graf tak berarah yang terdiri dari 5 buah titik dan 7 buah jalur yang menghubungkan antar dua buah titik. Algoritma Djikstra digunakan untuk mencari jarak terpendek dari sebuah titik ke titik lainnya pada graf tak berarah tersebut.

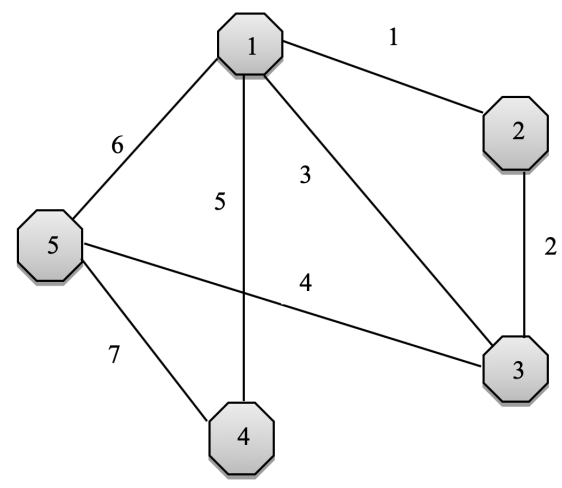

Gambar 2. Contoh Graf Tak Berarah

Berdasarkan contoh pada Gambar 1 tersebut merupakan contoh sebuah graf tak berarah yang terdiri dari 5 buah titik dan 7 buah jalur yang menghubungkan antar dua buah titik. Titik awal pencarian adalah titik 1 dengan tujuan yaitu titik 4 dan akan dicari jarak terpendek yang dapat ditempuh dari titik 1 untuk menuju titik 4. Berdasarkan tabel 1 penjelasan graf menggunakan algoritma Dijkstra.

Tabel 2. Penjelasan Graf Menggunakan Algoritma Dijkstra.

\begin{tabular}{|c|c|c|c|c|c|c|c|c|c|c|c|}
\hline \multirow{3}{*}{ Jalur } & \multicolumn{5}{|c|}{ Inisial Jalur } & \multirow{3}{*}{ Titik } & \multirow{2}{*}{\multicolumn{5}{|c|}{$\mathbf{l}(\mathbf{i}, \mathbf{j})$}} \\
\hline & 1 & 2 & 3 & 4 & 5 & & & & & & \\
\hline & 0 & 0 & 0 & 0 & 0 & & 1 & 2 & 3 & 4 & 5 \\
\hline 1 & 1 & 0 & 0 & 0 & 0 & 1 & $\mathrm{X}$ & $\mathrm{X}$ & $\mathrm{x}$ & $X$ & $\mathrm{x}$ \\
\hline $1-2$ & 1 & 1 & 0 & 0 & 0 & 2 & 1 & $\mathrm{X}$ & $\mathrm{x}$ & $\mathrm{X}$ & $\mathrm{x}$ \\
\hline $2-3$ & 0 & 1 & 1 & 0 & 0 & 3 & 3 & 2 & $\mathrm{x}$ & $\mathrm{x}$ & $\mathrm{x}$ \\
\hline $3-5$ & 0 & 0 & 1 & 0 & 1 & 4 & 5 & $\mathrm{x}$ & $\mathrm{x}$ & $\mathrm{x}$ & 7 \\
\hline $5-4$ & 0 & 0 & 0 & 1 & 1 & 5 & 6 & $\mathrm{x}$ & 4 & $\mathrm{x}$ & $\mathrm{x}$ \\
\hline
\end{tabular}

Pada Tabel 2 merupakan penyelesaian algoritma dijkstra jalur titik 1 ke titik 4 telah diselesaikan seperti pada penjelasan dan tabel di atas menurut perhitungan penelusuran graf sesuai langkah prosedural algoritma dijkstra. Pada baris pertama semua successor di set 0 artinya untuk memberi nilai pada sumber titik rute yang akan dijadikan rute dan ketidak terbatasaan untuk semua titik lain, yang menyatakan fakta bahwa tidak diketahui lintasan manapun. Untuk selanjutnya karena titik 1 sebagai sumber lintasan maka sudah pasti terpilih. Sehingga status set 0 berubah menjadi 1 . Titik 1 akan cek titik yang bertetanggaan langsung yaitu titik 2, 3, 4 dan 5. Dari situ dijkstra akan memilih yang mempunyai bobot terendah untuk menuju titik selanjutnya. Terpilih titik 2 dengan bobot 1 , set status 0 berubah menjadi 1 dan seterusnya. Maka dari pencarian jarak terpendek di atas, didapat lintasan yang terpendek berdasarkan pencarian dijkstra dari titik 1 ke 4 adalah melalui titik 1 langsung titik 4 dengan bobot lintasan 5 . 


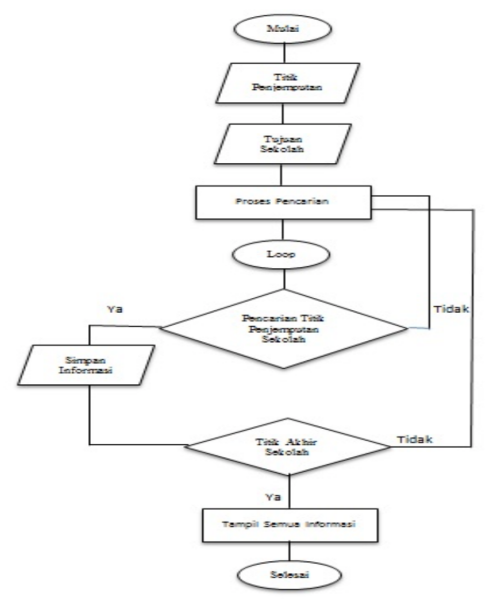

Gambar 3. Flowchart Sistem

\subsection{Android}

Android adalah merupakan platform open source Android memberikan pengembangan kebebasan untuk berkontrubusi pada pertumbuhan yang cepat dari pasar android [9]. Sistem operasi android dibangun diatas kernel linux, kerangka aplikasi terdiri dari Dalvik Virtual Machine yang menjalankan file. dex, sedangkan aplikasi ditulis dalam bahasa pemrograman java menggunakan android SDK yang dikompilasi menjadi DEX (Dalvix Executable) dan dikemas menjadi APK (Android Package).

\subsection{Location Based Service}

Merupakan suatu layanan informasi yang dapat diakses dengan melalui perangkat mobile dan jaringan selular juga memiliki kemampuan untuk memanfaatkan lokasi posisi perangkat mobile. Setiap layanan aplikasi yang memanfaatkan posisi terminal mobile Location Based Service adalah sebuah nama umum untuk sebuah layanan baru dimana informasi lokasi menjadi parameter utamanya [10].

\section{HASIL DAN PEMBAHASAN}

User akan menginputkan titik penjemputan dan tujuan sekolah yang akan dikunjungi. Setelah mengiputkan semua data-data yang dibutuhkan maka sistem akan mulai melakukan pencarian informasi transportasi (Bus Sekolah). Titik penjemputan dan bus sekolah yang akan digunakan oleh user untuk menuju sekolah yang akan dikunjungi, jika informasi yang ditemukan berkaitan dengan tujuan sekolah yang akan dikunjungi maka sistem akan menampung informasi tersebut kedalam Array, proses tersebut akan berulang sampai sistem mendapatkan informasi tujuan ke sekolah, kemudian informasi yang ditampung didalam Array akan ditampilkan, sehingga user bisa mendapatkan informasi detail tentang transportasi (Bus Sekolah) yang akan digunakan. Pada Gambar 3 dibawah adalah flowchart system yang menjelaskan tentang bagaimana system berjalan antar jemput siswa dan penentuan jalur lokasi penjemputan.

\subsection{Design Tampilan Aplikasi}

Pada Gambar 4 ini memiliki tombol login siswa yang di peruntukan untuk hak akses pada siswa. Dan login driver diperuntukan untuk supir dan terdapat akses login dari login siswa dan login driver.

Pada Gambar 5 dibawah terdapat akses untuk siswa, terdiri dari penetapan lokasi siswa, tujuan SMK Muhammadiyah Bumiayu dan posisi mobil jemputan. Pada tombol akses khusus driver ditujukan untuk memasuki menu khusus driver.

Pada Gambar 6 dibawah terdapat menu khusus driver yang menampilkan daftar nama siswa yang memesan penjemputan dan tombol tentukan jemputan untuk menentukan arah penjemputan siswa yang terdekat 


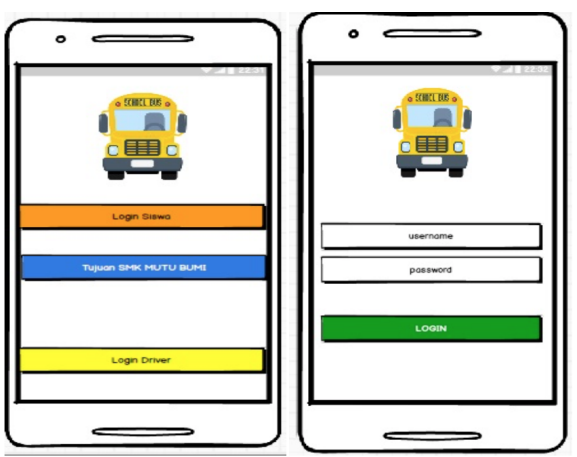

Gambar 4. Tombol Login Siswa, Driver dan Akses Login

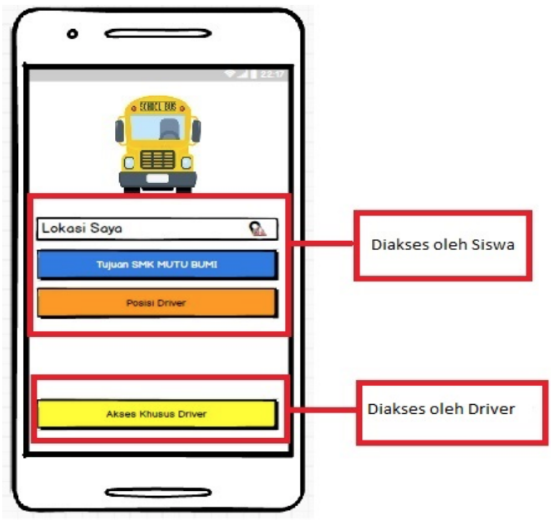

Gambar 5. Tombol khusus yang di akses oleh Siswa \& Driver

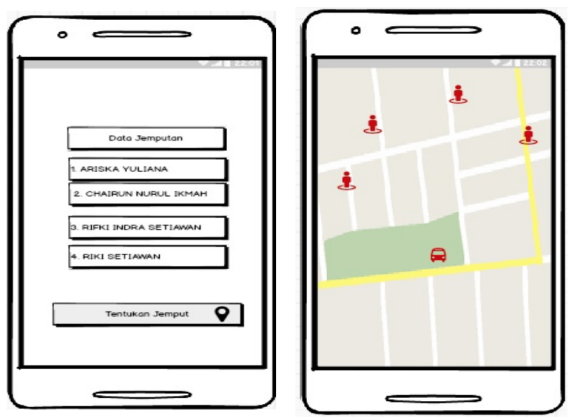

Gambar 6. Daftar Antrian Siswa dan Penetapan Pilihan Penjemputan Siswa

menggunakan metode Dijkstra dan menampilkan posisi lokasi penjemputan siswa dan selanjutnya program otomatis menentukan lokasi siswa yang terdekat terlebih dahulu.

\section{KESIMPULAN}

Berdasarkan analisis terhadap hasil pengujian system Penentuan rute optimal pada kegiatan penjemputan siswa SMK Muhammadiyah Bumiayu dengan menggunakan algoritma dijkstra, maka dapat ditarik kesimpulan adalah di dalam Dijkstra itu sendiri merupakan salah satu algoritma yang digunakan untuk mencari jarak terpendek, untuk menentukan jalur lokasi penjemput antar siswa. Pengembangan sistem informasi yang dibuat dengan menggunakan Android digunakan untuk penentuan jalur lokasi penjemput siswa (Halte). Hasil 
yang didapatkan dari penentuan jalur lokasi penjemputan siswa adalah mampu menemukan jarak terpendek dan jarak terpendek alternatif ketika terjadi hambatan (pemblokiran jalan dan Kemacetan) pada jalur terpendek utama dan juga dapat mengetahui estimasi waktu tempuhnya. Tujuannya dan manfaat dengan adanya aplikasi penentuan jalur lokasi penjemputan dengan menggunakan Algoritma Dijkstra berbasis mobile adalah untuk menentukan efesiensi rute penjemputan berdasarkan halte sekolah, waktu tempuh dan jumlah penumpang sedangkan Manfaat adalah untuk mengguranggi angka indek keterlambatan siswa, memberikan kemudahan akses kepada siswa-siswi SMK Muhammadiyah Bumiayu untuk pepesanan penjemputan, memberikan efisiensi waktu penjemputan siswa dan meningkatkan nilai jual SMK Muhammadiyah Bumiayu.

\section{DAFTAR PUSTAKA}

[1] C. Agustina and T. Wahyudi, "Aplikasi game pendidikan berbasis android untuk memperkenalkan pakaian adat indonesia," Indonesian Journal on Software Engineering, vol. 1, no. 1, p. 1-8.

[2] R. Angrarian, A. Suprayogi, and B. Yuwono, "Pembuatan aplikasi mobile gis berbasis android untuk informasi pariwisata di kabupaten gunungkidul," Jurnal Geodesi Undip, vol. 4, no. Oktober, p. 43-51. [Online]. Available: https://doi.org/10.1007/s11280-007-0038-5

[3] L. Bento, D. Boccardo, R. Machado, F. Miyazawa, V. Sá, and J. Szwarcfiter, "Dijkstra graphs," Discrete Applied Mathematics, vol. 227, p. 11. [Online]. Available: https://doi.org/10.1016/j.dam.2017.07.033

[4] W. Casteren, "The waterfall model and agile methodologies : A comparison by project characteristics," p. 10-13. [Online]. Available: https://doi.org/10.13140/RG.2.2.36825.72805

[5] Y. Chen, S. Shen, T. Chen, and R. Yang, "Path optimization study for vehicles evacuation based on dijkstra algorithm," Procedia Engineering, vol. 71, p. 159-165. [Online]. Available: https://doi.org/10.1016/j.proeng.2014.04.023

[6] Y. Dinitz and R. Itzhak, "Hybrid bellman-ford-dijkstra algorithm," Journal of Discrete Algorithms, vol. 42, p. 35-44. [Online]. Available: https://doi.org/10.1016/j.jda.2017.01.001

[7] A. Fadlil, R. Umar, and A. Budiman, "Perancangan sistem notifikasi mobile berbasis android sebagai bentuk peningkatan kualitas layanan pembayaran. prosiding snst ke-9 tahun,” p. 2849-2856. [Online]. Available: https://doi.org/10.1360/N972017-00542

[8] A. Hanggoro, R. Kridalukmana, and K. Martono, "Pembuatan aplikasi permainan "jakarta bersih" berbasis unity," Jurnal Teknologi Dan Sistem Komputer, vol. 3, no. 4, p. 503-511.

[9] A. Juansyah, "Pembangunan aplikasi child tracker berbasis assisted - global positioning system (gps) dengan platform android," Jurnal Ilmiah Komputer Dan Informatika (KOMPUTA, vol. 1, no. 1, p. 1-8.

[10] H. N. Lengkong, A. A. Sinsuw, and A. L, "Perancangan penunjuk rute pada kendaraan pribadi menggunakan aplikasi mobile gis berbasis android yang terintegrasi pada google maps," Jurnal Teknik Elektro Dan Komputer, vol. 4, no. 2, p. 18-25. 